\title{
The Role of Big Mitogen-Activated Protein Kinase 1 (BMK1) / Extracellular Signal-Regulated Kinase 5 (ERK5) in the Pathogenesis and Progression of Atherosclerosis
}

\author{
Masanori Yoshizumi ${ }^{1, *}$, Yoji Kyotani ${ }^{1}$, Jing Zhao ${ }^{1}$, Kosuke Nagayama ${ }^{1}$, Satoyasu Ito ${ }^{1}$, Yuichi Tsuji ${ }^{1}$, \\ and Kentaro Ozawa ${ }^{1}$ \\ ${ }^{1}$ Department of Pharmacology, Nara Medical University School of Medicine, \\ Shijo-cho 840, Kashihara, Nara 634-8521, Japan
}

Received September 3, 2012; Accepted October 11, 2012

\begin{abstract}
Big mitogen-activated protein kinase 1 (BMK1), also known as extracellular signalregulated kinase 5 (ERK5), is a newly identified member of the mitogen-activated protein (MAP) kinase family. BMK1 has been reported to be sensitive to various neuro-humoral factors and oxidative stress in various cells. In this review, we focused on the role of BMK1 in atherosclerosis in a cultured rat aortic smooth muscle cell model. Treatment with platelet-derived growth factor caused vascular smooth muscle cell (VSMC) migration in a BMK1 activation-dependent manner. $\mathrm{H}_{2} \mathrm{O}_{2}$ caused BMK1 activation and VSMC death, including apoptosis of VSMCs. An inhibitory function for BMK1 against cell death from oxidative stress was discovered using siRNA techniques to downregulate the expression of BMK1. These findings suggest a role for BMK1 in the pathogenesis and/or progression of atherosclerosis.
\end{abstract}

Keywords: big mitogen-activated protein kinase 1 (BMK1) / extracellular signal-regulated kinase 5 (ERK5), atherosclerosis, vascular smooth muscle cell, signal transduction

\section{Introduction}

Recent progress in molecular biology and signal transduction research has helped reveal the mechanisms of pathogenesis and progression of atherosclerosis. According to the "response to injury hypothesis" put forth by Ross (1), the initial step of atherogenesis is intimal injury and the subsequent platelet aggregation and leukocyte invasion beneath the endothelial monolayer. Further, through macrophage activation and foam cell formation, vascular smooth muscle cell (VSMC) proliferation and migration lead to atherosclerosis. Various neuro-humoral factors such as noradrenaline and angiotensin II (Ang II) or cytokines such as interleukins and TNF- $\alpha$ have been reported to be involved in these progressive processes (2, $3)$. We have been studying the intracellular mechanisms

*Corresponding author. yoshizu@naramed-u.ac.jp Published online in J-STAGE on November 20, 2012 (in advance) doi: $10.1254 /$ jphs.12R11CP

Invited article of the initiation and progression of atherosclerosis and have investigated possible strategies to inhibit the signal transduction cascades involved in this process in an attempt to devise therapies for atherosclerosis.

2. Signal transduction of mitogen-activated protein (MAP) kinases and the role of BMK1 in plateletderived growth factor (PDGF)-induced VSMC migration

MAP kinases are protein serine/threonine kinases that play an important role in cell differentiation, growth, apoptosis, and the regulation of a variety of transcription factors and gene expression. MAP kinases are activated by phosphorylation on threonine $(\mathrm{T})$ and tyrosine $(\mathrm{Y})$ residues within a $\mathrm{T}-\mathrm{X}-\mathrm{Y}$ phosphorylation motif, where " $\mathrm{X}$ " can be glutamine (E), proline $(\mathrm{P})$, or glycine $(\mathrm{G})$. To date, 4 major classes of dual-specificity MAP kinases have been defined, based on their activation motifs (TEY, TPY, and TGY), which are termed extracellular signalregulated kinase 1/2 (ERK1/2) and big MAP kinase 1 (BMK1, also called ERK5), c-Jun N-terminal protein 
kinase $[\mathrm{JNK}$, also called stress-activated protein kinase (SAPK)], and p38 (Fig. 1). BMK1 is a newly identified member of the MAP kinase family with a large $\mathrm{COOH}-$ terminal and a unique loop 12 sequence, which shares the TEY activation motif with ERK1/2, but is activated by MAP kinase and ERK kinase 5 (MEK5) $(4,5)$. Previously, we reported that BMK1 is activated by $\mathrm{H}_{2} \mathrm{O}_{2}$, and this activation may be related to cell survival in PC12 cells (6). In addition, we found that BMK1 is rapidly activated by high glucose concentrations in rat mesangial cells and in the glomeruli of Otsuka Long-Evans Tokushima fatty (OLETF) rats, a diabetic rat model (7). These findings suggested that BMK1 is involved in the pathogenesis of diabetic nephropathy. It is well documented that the activation of MAP kinases leads to the activation of downstream protein kinases and transcription factors, which then results in the phenotypic modulation of various cellular processes such as differentiation, proliferation, and apoptosis. Therefore, we have been investigating the role of BMK1 in the pathogenesis of atherosclerosis by using cultured rat aortic smooth muscle cells (RASMCs).

PDGF is a growth factor for mesenchymal cells such as fibroblasts, smooth muscle cells, and glial cells, which causes cellular migration or proliferation (8). PDGF is mainly produced in megakaryocytes; however, recent findings revealed that many types of cells such as epithelial cells or endothelial cells can also produce PDGF. PDGF is secreted in response to inflammatory stimuli, subsequently promoting wound healing through VSMC migration. It has been reported that PDGF induces VSMC

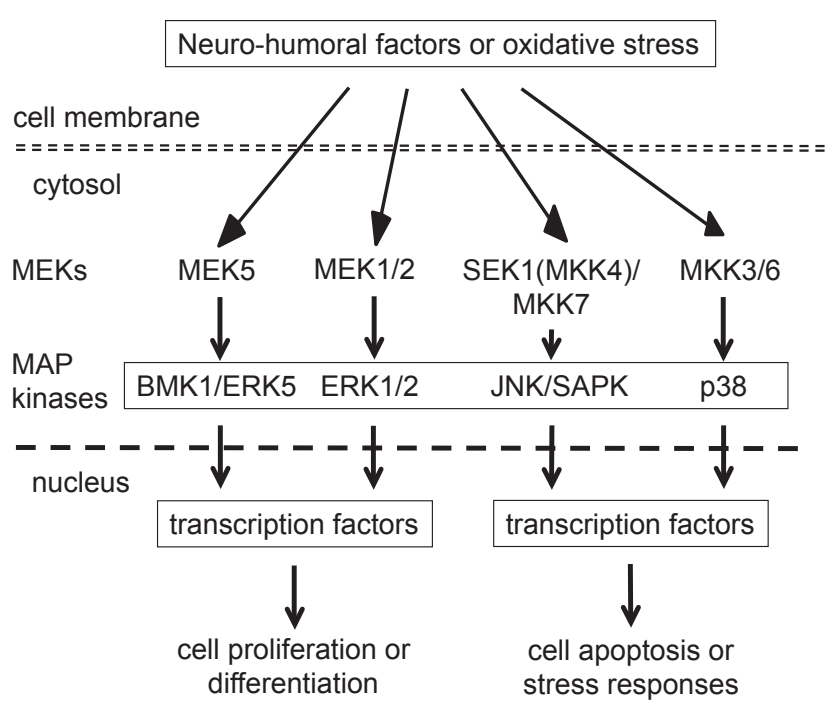

Fig. 1. Signal transduction cascades for mitogen-activated protein (MAP) kinases in vascular smooth muscle cells. MEKs are MAP kinase and ERK kinases. migration and the development of neo-intimal thickness in a rat model of atherosclerosis, the femoral artery balloon injury model (9). Therefore, we investigated the involvement of BMK1 in PDGF-induced VSMC migration using RASMCs (10). To evaluate the magnitude of PDGF-stimulated BMK1 activation in VSMCs, growtharrested RASMCs were treated with $10 \mathrm{ng} / \mathrm{ml}$ PDGF for various times, for up to $60 \mathrm{~min}$. BMK1 was rapidly phosphorylated by PDGF and reached its maximal response within 5 - 10 min. PDGF-induced BMK1 activation was increased in a concentration-dependent manner (over a PDGF concentration range of $0.3-30 \mathrm{ng} / \mathrm{ml}$ ). In addition, our studies also revealed that PDGF-induced BMK1 activation requires phosphorylation of Gab1, an adaptor protein, and its association with SHP-2, a tyrosine phosphatase. Moreover, the phosphatase activity of SHP2 was important for BMK1 activation. These data suggested that the Gab1-SHP-2-MEK5-BMK1 pathway is likely a crucial target for the control and regulation of PDGF-induced VSMC migration (Fig. 2). Because BMK1 is considered to be phosphorylated and activated by MAP kinase kinase $5 \alpha$ (MEK5 $\alpha$ ) with high specificity, we used an adenoviral vector carrying a dominantnegative (DN)-MEK5 $\alpha$ to inhibit PDGF-induced BMK1 activation. Our results indicated that BMK1 activation and PDGF-stimulated RASMC migration were inhibited in cells infected with DN-MEK5 $\alpha$, compared with the lacZ-infected control cells. In the in vivo experiments, immunofluorescence staining for phosphorylated BMK1

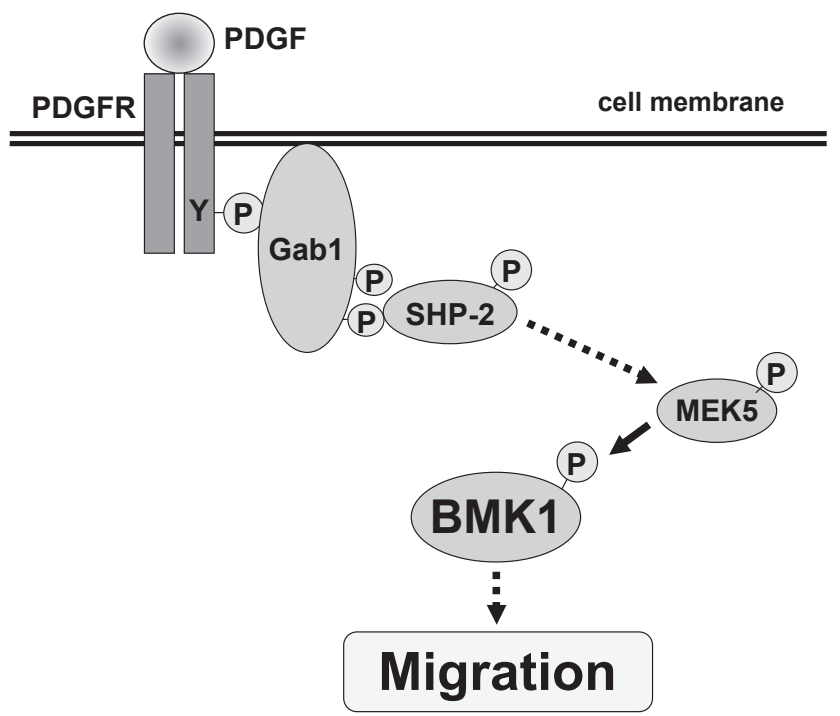

Fig. 2. Intracellular signal transduction mechanism of plateletderived growth factor (PDGF)-induced vascular smooth muscle cell migration through BMK1 activation. Abbreviations: PDGFR, PDGF receptor; Gab1, Grb-2-associated binder 1; SHP-2, SH-2 containing protein tyrosine phosphatase-2. 
revealed that BMK1 activation and BMK1 phosphorylation had increased in the cuff-injured model of the rat femoral artery, compared to the levels in control, shamoperated arteries. These observations indicated that BMK1 activation is implicated in VSMC migration in vivo and in vascular remodeling related to inflammatory processes.

\section{Pathophysiological role of oxidative stress-mediat- ed BMK1 activation in cultured RASMCs}

Because the phrase "oxidative stress" is currently very popular in many research fields, understanding its pathophysiological roles requires a clear definition of its meaning at the molecular level. While oxygen is an essential molecule for aerobic metabolism, it also has adverse properties, such as the capacity to induce cell damage and toxicity. Among the several products of oxidation-reduction reactions, oxygen-derived free radicals are called reactive oxygen species (ROS) and nitrogen-derived free radicals are called reactive nitrogen species (RNS). ROS include the superoxide anion $\left(\mathrm{O}_{2}{ }^{--}\right)$, the hydroxyl radical $\left({ }^{\circ} \mathrm{OH}\right)$, hydrogen peroxide $\left(\mathrm{H}_{2} \mathrm{O}_{2}\right)$, and lipid peroxides, whereas RNS include nitric oxide $\left(\mathrm{NO}^{\circ}\right)$ and peroxynitrite $\left(\mathrm{ONOO}^{-}\right)$. Recently, ROS, including $\mathrm{O}_{2}{ }^{-{ }^{-}}$and $\mathrm{H}_{2} \mathrm{O}_{2}$, have been reported to be produced in VSMCs, endothelial cells, and cardiomyocytes $(1,11)$. Many researchers suggested that NADH/NADPH oxidase is a major source of ROS generation in VSMCs (11, 12). The vascular NADH/NADPH oxidases share some similarities with components of the multi-subunit enzyme complex that is activated by growth factors like PDGF and by vasoactive peptides such as Ang II and endothelin. A recent study suggested that $\mathrm{p} 22 \mathrm{phox}$, one of the major subunits of NADH/NADPH oxidase, plays an important role in ROS generation by demonstrating that transfection with p22phox antisense oligonucleotides significantly inhibited the Ang II-mediated superoxide generation in VSMCs (13). Recently, the gene encoding for nox-1 was cloned and identified as a homolog of the gp91phox gene, which encodes for a subunit of NADH/ NADPH oxidase in phagocytes (14). It has been confirmed that nox-1 is also expressed in VSMCs and preserves the main functional regions of $g p 91$ phox, including the flavoprotein domain and the 2 heme-binding domains (15). Because transfection with nox-lantisense oligonucleotides inhibited the effect of Ang II-induced superoxide generation and serum-induced VSMC proliferation $(13,16)$, it was suggested that nox-1 is an important subunit of the NADH/NADPH oxidase in VSMCs. In an electron paramagnetic resonance (EPR) study, we also demonstrated that Ang II and endothelin stimulate ${ }^{\circ} \mathrm{OH}$ radical generation in VSMCs and that treatment with antioxidants inhibit these effects (17).

VSMC apoptosis is recognized to be of importance in atherosclerosis. Recent data have shown that apoptosis is implicated in human vascular calcification and that apoptotic bodies initiate vascular calcification (18). Some research has also indicate that VSMCs may be induced by signals and mechanisms that are not yet well defined to release matrix vesicles, which could concentrate calcium and phosphate to allow crystal nucleation and thus lead to mineralization. Although BMK1 is sensitive to oxidative stresses, as mentioned above, its role in the pathogenesis of atherosclerosis is not fully understood. Therefore, we investigated the involvement of BMK1 in oxidative stress-induced cell death using cultured RASMCs (19). We first investigated the effect of $\mathrm{H}_{2} \mathrm{O}_{2}$ on the death of RASMCs using a MTT assay. The viability of RASMCs was significantly reduced with an increase in the time of treatment with $\mathrm{H}_{2} \mathrm{O}_{2}$. At each time point, the cell viability at $1 \mathrm{mM} \mathrm{H}_{2} \mathrm{O}_{2}$ was lower than that at $0.3 \mathrm{mM} \mathrm{H}_{2} \mathrm{O}_{2}$. These results indicate that both timeand concentration-dependent effects of $\mathrm{H}_{2} \mathrm{O}_{2}$ on cell viability in RASMCs are observed. We next investigated the effect of $\mathrm{H}_{2} \mathrm{O}_{2}$ on the activation of BMK1 in RASMCs by western blotting analysis of phosphorylated BMK1. BMK1 was activated using $1 \mathrm{mM} \mathrm{H}_{2} \mathrm{O}_{2}$, with a peak at 40 min. Forty minutes after incubation with $\mathrm{H}_{2} \mathrm{O}_{2}$, we found that the activation of BMK1 occurred in a concentration-dependent manner up to $1 \mathrm{mM}$ of $\mathrm{H}_{2} \mathrm{O}_{2}$. The activity of c-Src, an upstream tyrosine kinase, also increased with increasing the time of stimulation with $1 \mathrm{mM} \mathrm{H}_{2} \mathrm{O}_{2}$, reaching a peak at $40 \mathrm{~min}$. c-Src, which was originally identified as an oncogene, works as a molecular switch by modulating cellular functions as a result of a conformational change in its structure induced via phosphorylation or association with other proteins (20). After incubation with $\mathrm{H}_{2} \mathrm{O}_{2}$ for $40 \mathrm{~min}$, c-Src was activated in a concentration-dependent manner for up to $1 \mathrm{mM}$ of $\mathrm{H}_{2} \mathrm{O}_{2}$. These results indicated that both $\mathrm{c}-\mathrm{Src}$ and BMK1 are sensitive to oxidative stress. We also found that PP2, a c-Src inhibitor, decreased the $\mathrm{H}_{2} \mathrm{O}_{2}$-mediated BMK1 activation in RASMCs. These findings strongly suggest that c-Src is involved in $\mathrm{H}_{2} \mathrm{O}_{2}$-induced $\mathrm{BMK} 1$ activation in RASMCs. To better understand the endogenous function of BMK1 in $\mathrm{H}_{2} \mathrm{O}_{2}$-induced RASMC death, we also used a small interfering RNA (siRNA) technique to inhibit BMK1 expression and assessed cell viability in the presence of decrease in BMK1 activity. The transfection efficiency of BMK1 knockdown increased with an increase in the siRNA concentration and reached as high as $80 \%$ at a concentration of $10 \mathrm{nM}$ siRNA. To avoid the occurrence of off-target phenomenon due to the high homology of BMK1 and ERK1/2 genes, we evaluated the ERK1/2 expression in the same cells. It was con- 
firmed that ERK1/2 expression was not changed in cells transfected with BMK1 siRNA, at any of the siRNA concentrations tested (Fig. 3). Using BMK1 siRNAtransfected cells, we evaluated $\mathrm{H}_{2} \mathrm{O}_{2}$-induced RASMC death by an MTT assay. RASMC death occurred to a greater degree in BMK1 siRNA-transfected cells than in non-transfected RASMCs. PP2 also promoted the RASMC death induced by $\mathrm{H}_{2} \mathrm{O}_{2}$ treatment. These results suggest that c-Src, as well as BMK1, played a positive role in sustaining cell survival. On the basis of the results obtained in the presence of inhibitors and siRNAs for cSrc and BMK1, we proposed that c-Src and BMK1 work as cell protectors or as survival factors for RASMCs. cSrc and BMK1 may play defensive and resistive roles against oxidative stress-induced cell death in RASMCs (Fig. 4).

\section{Pathophysiological significance of BMK1 in other diseases}

Recently, studies using gene-targeted mice lacking either BMK1, or other components that relate to the BMK1 cascade, have revealed that BMK1 signaling is critical for angiogenesis, cardiac development, and the maintenance of vascular integrity during a crucial period in development (4). In adulthood, BMK1 is involved in the survival of the vascular endothelial cells and in the maintenance of vascular integrity (4). On the other hand, ERK5 expression is increased in human cancer tissues, suggesting that ERK5 is involved in the functional regulation of several oncogenes (21). In our previous study,

\section{BMK1 gene silencing by using siRNA}

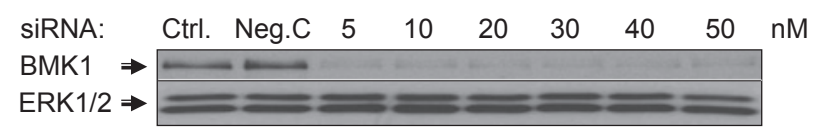

$\mathrm{H}_{2} \mathrm{O}_{2}$-induced cell death was increased by $\mathrm{BMK} 1$ knockdown

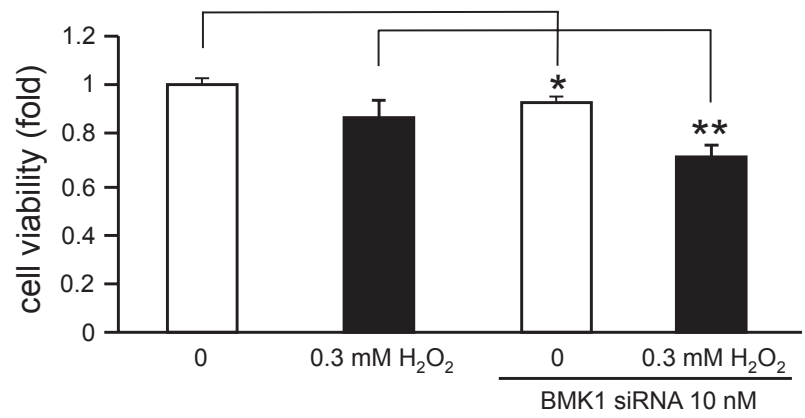

Fig. 3. BMK1 gene silencing by using siRNA augmented $\mathrm{H}_{2} \mathrm{O}_{2}$ induced vascular smooth muscle cell death. The asterisks represent significant differences compared with the value of the control $(* P<0.05, * * P<0.01)$. we found that BMK1 is involved in the survival of PC12 cells, a model system for neuronal cells (6). Reports from other laboratories noted that BMK1 is activated by neurotrophin or epidermal growth factor in neuronal cells, and this activation results in neurite outgrowth or neuroprotection after cerebral infarction $(22,23)$. In vascular endothelial cells, BMK1 activation provides protection from apoptosis $(24,25)$. We also found that laminar blood flow activates BMK1, which, in turn results in the inhibition of endothelial cell apoptosis through the inhibition of TNF- $\alpha$-induced JNK activation (26). In the kidney, we found, for the first time, that high glucose levels cause activation of BMK1 in cultured rat mesangial cells and also observed the activation of BMK1 in the glomeruli of OLETF rats, a model of type-2 diabetes mellitus (7). More recently, we also found that activation of the mineralocorticoid receptor is involved in high glucose-induced BMK1 activation and in proliferation of cultured rat mesangial cells (27). It was also reported that Ang II or oxidative stress may cause BMK1 activation in the glomeruli in the model of chronic nephropathy, using an anti-Thy-1 antibody (28).

\section{Future directions}

Since the discovery and cloning of BMK1/ERK5 in 1995, further research of the cellular functions of this molecule has been facilitated by the development of knockout mice, specific antibodies, specific inhibitors, and siRNAs. We have investigated the pathophysiologi-

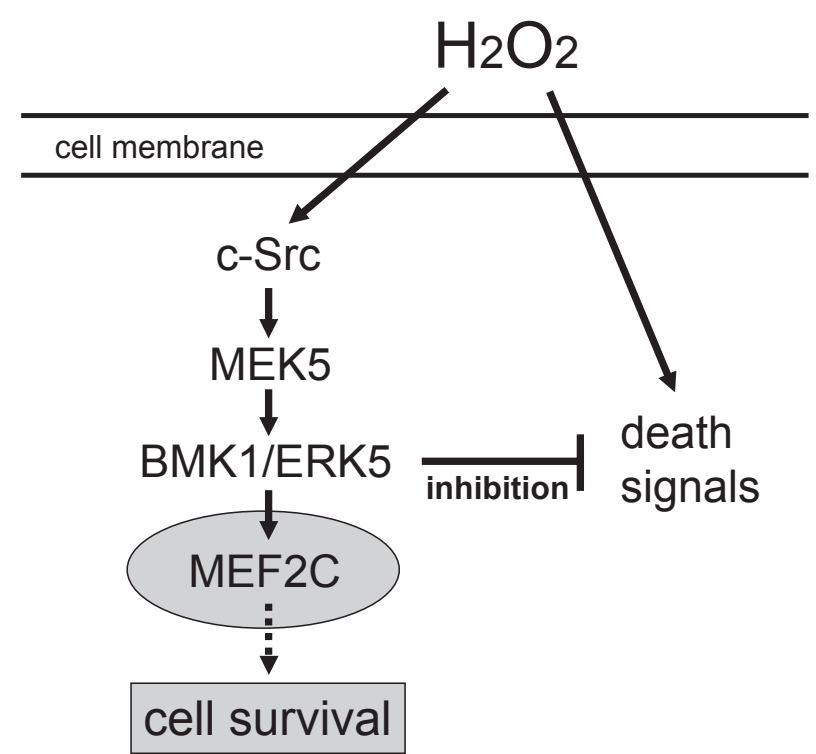

Fig. 4. Intracellular signal transduction mechanism of $\mathrm{H}_{2} \mathrm{O}_{2}$-induced vascular smooth muscle cell (VSMC) survival through BMK1 activation. BMK1 protects VSMC from oxidative damage. 
cal role of this unique molecule for several years. Even though BMK1/ERK5 is highly homologous to ERK1/2, it has non-redundant and specific functions in signal transduction in cells. To date, BMK1 has been demonstrated to serve a protective function for cells in some pathophysiological conditions and provides cells with resistance against death signals, thereby promoting cell survival. In other contexts, BMK1/ERK5 has roles in differentiation and proliferation and can contribute to the pathogenesis and progression of diseases. Future studies focused on the BMK1-associated molecular pathways will help reveal the function of BMK1 in various pathological conditions and will aid the development of therapeutic strategies targeting BMK1/ERK5 in various diseases.

\section{References}

1 Ross R. Atherosclerosis - an inflammatory disease. N Engl J Med. 1999;340:115-126.

2 Yoshizumi M, Tsuchiya K, Tamaki T. Signal transduction of reactive oxygen species and mitogen-activated protein kinases in cardiovascular disease. J Med Invest. 2001;48:11-24.

3 Abe J, Berk BC. Reactive oxygen species as mediators of signal transduction in cardiovascular disease. Trends Cardiovasc Med. 1998;8:59-64.

4 Hayashi M, Lee JD. Role of the BMK1/ERK5 signaling pathway: lessons from knockout mice. J Mol Med. 2004;82:800-808.

5 Nishimoto S, Nishida E. MAPK signaling: ERK5 versus ERK1/2. EMBO Rep. 2006; 7:782-786.

6 Suzaki Y, Yoshizumi M, Kagami S, Koyama AH, Taketani Y, Houchi $\mathrm{H}$, et al. Hydrogen peroxide stimulates c-Src-mediated big mitogen-activated protein kinase 1 (BMK1) and the MEF2C signaling pathway in $\mathrm{PC} 12$ cells. Potential role in cell survival following oxidative insults. J Biol Chem. 2002;277:9614-9621.

7 Suzaki Y, Yoshizumi M, Kagami S, Nishiyama A, Ozawa Y, Kyaw M, et al. BMK1 is activated in glomeruli of diabetic rats and in mesangial cells by high glucose conditions. Kidney Int. 2004;65:1749-1760.

8 Grotendorst GR, Seppa HE, Kleinman HK, Martin GR. Attachment of smooth muscle cells to collagen and their migration toward platelet-derived growth factor. Proc Natl Acad Sci U S A. 1981;78:3669-3672.

9 Jawien A, Bowen-Pope DF, Lindner V, Schwartz SM, Clowes AW. Platelet-derived growth factor promotes smooth muscle migration and intimal thickening in a rat model of balloon angioplasty. J Clin Invest. 1992;89:507-511.

10 Izawa Y, Yoshizumi M, Ishizawa K, Fujita Y, Kondo S, Kagami $\mathrm{S}$, et al. Big mitogen-activated protein kinase 1 (BMK1)/extracellular signal-regulated kinase 5 (ERK5) is involved in plateletderived growth factor (PDGF)-induced vascular smooth muscle cell migration. Hypertens Res. 2007;30:1107-1117.

11 Griendling KK, Sorescu D, Ushio-Fukai M. NAD(P)H oxidase: role in cardiovascular biology and disease. Circ Res. 2000;86: 494-501.

12 Griendling KK, Sorescu D, Lassègue B, Ushio-Fukai M. Modulation of protein kinase activity and gene expression by reactive oxygen species and their role in vascular physiology and pathophysiology. Arterioscler Thromb Vasc Biol. 2000;20: 2175-2183.

13 Ushio-Fukai M, Zafari AM, Fukui T, Ishizaka N, Griendling KK. p22phox is a critical component of the superoxide-generating $\mathrm{NADH} / \mathrm{NADPH}$ oxidase system and regulates angiotensin IIinduced hypertrophy in vascular smooth muscle cells. J Biol Chem. 1996;271:23317-23321.

14 Lambeth JD, Cheng G, Arnold RS, Edens WA. Novel homologs of gp91phox. Trends Biochem Sci. 2000;25:459-461.

15 Lassegue B, Sorescu D, Szöcs K, Yin Q, Akers M, Zhang Y, et al. Novel gp91(phox) homologues in vascular smooth muscle cells: nox 1 mediates angiotensin II-induced superoxide formation and redox-sensitive signaling pathways. Circ Res. 2001;88:888-894.

16 Matsuno K, Yamada H, Iwata K, Jin D, Katsuyama M, Matsuki $\mathrm{M}$, et al. Nox1 is involved in angiotensin II-mediated hypertension: a study in Nox1-deficient mice. Circulation. 2005;112: 2677-2685.

17 Kyaw M, Yoshizumi M, Tsuchiya K, Kirima K, Tamaki T. Antioxidants inhibit JNK and p38 MAPK activation but not ERK 1/2 activation by angiotensin II in rat aortic smooth muscle cells. Hypertens Res. 2001;24:251-261.

18 Pruodfoot D, Skepper JN, Hegyi L, Bennett MR, Shanahan CM, Weissberg PL. Apoptosis regulates human vascular calcification in vitro. Circ Res. 2000;87:1055-1062.

19 Zhao J, Kyotani Y, Itoh S, Nakayama H, Isosaki M, Yoshizumi M. Big mitogen-activated protein kinase 1 protects cultured rat aortic smooth muscle cell from oxidative damage. J Pharmacol Sci. 2011;116:173-180.

20 Brown MT, Cooper JA. Regulation, substrates and functions of src. Biochem Biophys Acta. 1996;1287:121-149.

21 Wang X, Toumier C. Regulation of cellular functions by the ERK5 signaling pathway. Cell Signal. 2006;18:753-760.

22 Cavanaugh JE, Ham J, Hetman M, Poser S, Yan C, Xia Z. Differential regulation of mitogen-activated protein kinases ERK1/2 and ERK 5 by neurotrophins, neuronal activity, and camp in neurons. J Neurosci. 2001;21:434-443.

23 Kamakura S, Moriguchi T, Nishida E. Activation of the protein kinase ERK5/BMK1 by receptor tyrosine kinases. Identification and characterization of a signaling pathway to the nucleus. J Biol Chem. 1999;274:26563-26571.

24 Yan C, Takahashi M, Okuda M, Lee JD, Berk BC. Fluid shear stress stimulates big mitogen-activated protein kinase 1 (BMK1) activity in endothelial cells. Dependence on tyrosine kinases and intracellular calcium. J Biol Chem. 1999;274:143-150.

25 Pi X, Yan C, Berk BC. Big mitogen-activated protein kinase 1 (BMK1)/ERK5 protects endothelial cells from apoptosis. Circ Res. 2004;94:362-369.

26 Li L, Tatake RJ, Natarajan K, Taba Y, Garin G, Tai C, et al. Fluid shear stress inhibits TNF-mediated JNK activation via MEK5BMK1 in endothelial cells. Biochem Biophys Res Commun. 2008;370:159-163.

27 Liu G, Miyata K, Hitomi H, Yao L, Sun GP, Suzaki Y, et al. Involvement of mineralocorticoid receptor in high glucose-induced big mitogen-activated protein kinase 1 activation and mesangial cell proliferation. J Hypertens. 2010;28:536-542.

28 Urushihara M, Takamatsu M, Shimizu M, Kondo S, Kinoshita Y, Suga K, et al. ERK5 activation enhances mesangial cell viability and collagen matrix accumulation in rat progressive glomerulonephritis. Am J Physiol Renal Physiol. 2010;298:F167-F176. 